\title{
Mountain Waters: Using Chinese Landscape Thought As a Frame for Architectural Practice in China
}

Matthew Priestman RIBA, Priestman Architects Chongqing

\section{Abstract}

Working on many scales and types of projects in China at times of rapid change, the writer is founder of his own architectural practice Priestman Architects now based in Chongqing and is a PhD candidate at London's University of Westminster.

Environmental, socio-economic and spatial problems persist and metamorphose; the phenomenon of the burgeoning and dominant human habitat of the city is also faced with rapid change from new forms of occupation and technologies. Promoting hopeful visions of the unruly city and its interrelated fringes is a pressing need. This paper proposes an outline theoretical framework using ideas of cultural landscape in China to better frame and locate architectural work.

The paper starts with Living off Landscape by Francois Jullien which discusses the

Received: 15 March 2019

Accepted: 25 May 2019

Published: 20 November 2019

Publishing services provided by Knowledge

(c). This article is distributed under the terms of the Commons Attribution License, which permits unrestricted use and redistribution provided that the original author and source are credited.

Selection and Peer-review under the responsibility of the Architecture across Boundaries Conference Committee.

\section{G OPEN ACCESS} potency of Chinese ideas of landscape against the limitations of European landscape thought and includes a discussion of photography as the primary media beyond painting that is extending ideas of landscape. The paper considers the use of the path in classical Chinese landscape painting as a conceptual, cultural and physical thread linking the non-urban to the urban. There, the building - heroic object or urban component - can both accommodate exterior contexts and combine resonant interiorities to constitute a fertile field where social and private domains touch.

Keywords: Idea of Landscape, Architecture, Urbanism, practice in Modern China, Photography, Environmentalism

\section{Introduction}

The aim of this paper is to outline a theoretical framework for architectural practice in China, at a time of remarkable re-discovery and reinvention of its cultures. It uses Chinese landscape thought as a philosophical foundation and contemporary ideas of landscape as the material for design enquiries.

Our work in practice includes urban planning and new buildings, urban regeneration of streets and quarters, heritage and rural development projects. This covers many scales and functions for government and private clients. We try to mediate between the larger contexts of geography, policy, economics, culture and need and the diverse 
human interactions within buildings and cities working at the borders between public and private domains.

If Europe's post-war development could be summarized as a transition from rebuilding, heroic modernism, reaction and cultural anxiety and now to (hopefully) intelligent pluralism, then China is attempting all these phases at the same time with constantly changing emphases. The architect here operates in a shifting mist so often depicted in classical Chinese painting.

Beginning with Francois Jullien's recent essay Living off Landscape that compares European Landscape thought with the radically different classical Chinese thought formulations of 'Shan Shui' (the two Chinese characters used for 'landscape' literally translated as 'Mountain(s) Water(s)'), the paper responds to that essay's unanswered questions on modern European and Chinese landscape thinking. The media of photography as a new landscape art form, overarching ideas of environmentalism and digitally created terrains in 'Cyberia' have profoundly moved landscape thinking on, albeit differently explored in Europe and China.

Outlining a field of ideas of cultural landscape the paper focusses on the path as an existential, cultural, social and practical structure that entwines diverse realities. The idea of the path is extended into the city in the form of the problematic and promising domain of the modern street, which is shared by so many.

The path in the landscape -- the street in the city -- is used as the methodology for reviewing current work in the rapidly changing condition of contemporary China.
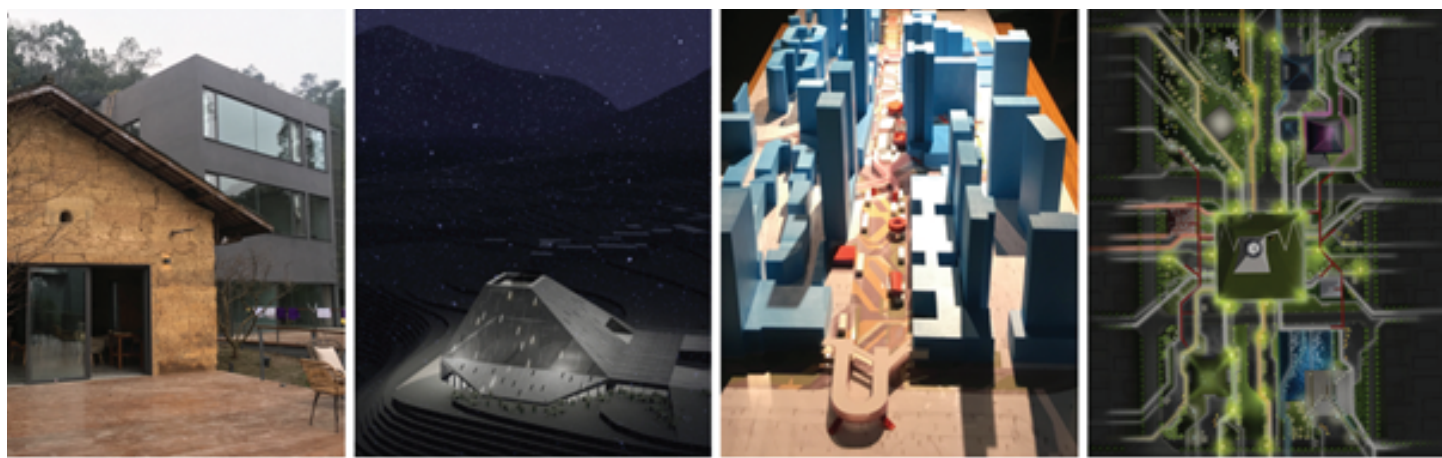

Priestman Architects: ongoing adaption, public buildings, urbanism \& city projects at a time of China's cultural resurgence

\section{The European and Chinese idea of Landscape}

In Living off Landscape, Francois Jullien, the French writer on philosophy and aesthetics, asserts that Europe -- initially through renaissance painting - only recently became aware of landscape, whereas in China landscape had arisen over a thousand years earlier. 
Examining Chinese landscape-thought, he articulates the potentiality that "..we might consider this thing called 'landscape' no longer as 'part' of the land that 'nature' presents to an 'observer', in the ordinary definition, but as a resource on which living (vivre) can indefinitely draw." (Prologue, p.x - Jullien, Francois., Living off Landscape, or the Unthought of in Reason (t.2018))

His critique of European thought on landscape is that firstly it arose almost in passing -- as the backdrop to events in the foreground. The idea of Landscape in Europe, he argues, is constrained by three underlying precepts (Chapter I, Expanse, View, Cutoff Jullien, Francois., Living off Landscape, or the Un-thought of in Reason (t.2018)): Firstly that is conceived as a selected part in relation to a whole (of land), secondly that there is a visual bias to it as something we view or look at. His third constraint is that it doesn't escape from subject -- object biases, where we the subjective observer are separated from the landscape object before us.

He next outlines the way language is used in China, through parataxis, conjoining different character-symbol-meanings. Hence the 'word' for landscape in Chinese is the combination of the two characters for 'Mountain(s)' and 'Water(s)'. Here already is an entirely different scope for the idea of landscape and inhabitation of it, with the correspondence of the immovable forms of mountain with the fluid formlessness of water, vapour and cloud. He compares this thinking: "We (Europeans) were not expecting this other possibility of thought. In truth, we had never even imagined it." (P.17 Chapter II, "Mountain(s)-Water(s)" Jullien, Francois., Living off Landscape, or the Un-thought of in Reason (t.2018)) and concludes "All landscape apprehended in this play of correlations is the entirety of the world in its vibrancy: not a world that beckons from Elsewhere but a world received in the to-and-fro of its respiration. This same tension of living is what Chinese painting captures in landscape." (P.26 Chapter II, "Mountain(s)-Water(s)" Jullien, Francois., Living off Landscape, or the Un-thought of in Reason (t.2018))

Jullien argues that landscape as articulated in Chinese thought extends beyond the seeing and viewing - as a locus of exchange - where the polarisation for instance of near-far or of permanence-transience speaks of the correlation between physicality and interiority and between the perceptual and the affectual. These appreciations could free us, has says, and "We can now better appreciate the usefulness of the Chinese theoretical apparatus. By looking at everything in terms of correlation it breaches the wall behind which Europe's psychological (insular) notion of the self-subject lies entrenched." (P.49 Chapter IV: When the Perceptual turns out to be Affectual - Jullien, Francois., Living off Landscape, or the Un-thought of in Reason (t.2018)) 
He focusses on the way that in Chinese thought Mountain-Waters entwines the realms of physicality, living and spirituality; "Thus landscape plunges us physically or, better yet, phenomenally - "between Heaven and Earth"; it plunges us raw into the fundamental interaction that endlessly promotes existence and conveys us to a clearingout and opening-up." (P.60 Chapter V: When 'Spirit' Emanates from the Physical - Jullien, Francois., Living off Landscape, or the Un-thought of in Reason (t.2018))

Jullien concludes his essay with a short design manifesto: "What matters is the advent of multiple polarities that set the world in tension and rescue it from impending uniformity, which will doom it to boredom by atony before relegating it to indifference." (P.125 Epilogue - Jullien, Francois., Living off Landscape, or the Un-thought of in Reason (t.2018)).

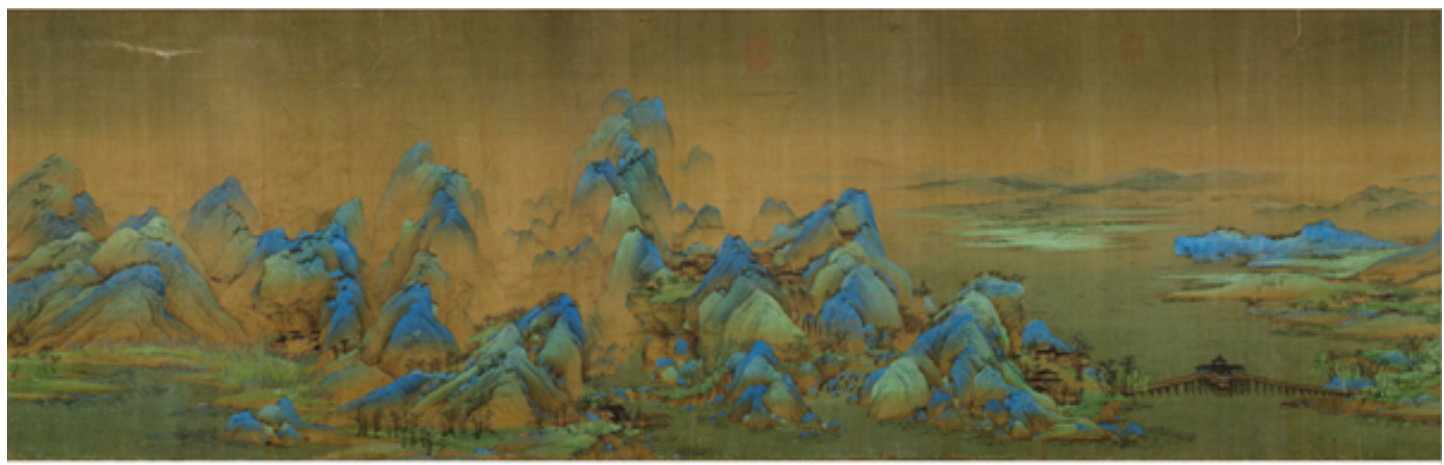

\section{Photography + Environmentalism What happened to the idea of landscape in Europe?}

Looking back again at the works of Nicolas Poussin, famously known for his landscapes, we are also drawn into his intense internal-external compositions where human passion and the environment are entwined - for instance in his Seven Sacraments (Poussin, Nicolas., (b. 1594) The Seven Sacraments -- the second series (1644 to 1648) is currently on loan at the National Gallery of Scotland, Edinburgh). As the popular writer Alain de Botton recently argues in 'Art for Therapy' (De Botton, Alain., Art for Therapy (2018)), we may correspond with works of art for powerful emotional reasons, that extends beyond works drily described as moments in a linear history of art. In Poussin's work the 'environment' is inhabited by us, and it emanates to us the assembled interplay of things.

Jullien observes that art in Europe declined to further develop ideas of landscape. Romanticism -- poignantly expressed in Caspar David Friedrich's The Wanderer Above The Sea Of Fog (Friedrich, Caspar David,. (b. 1774) The Wanderer Above The Sea Of 
Fog (1818)), had reaffirmed the (tragic) isolation of the individual in the subject -- object 'fold', or limitation, of Europe's landscape thought that Jullien describes. Impressionism focused on the phenomena of light (For example in the work of: William Turner (b. 1775), Claude Monet (b. 1840), Pierre Bonnard (b. 1867)), of seeing itself and haecceity. Juan Miro is passionate about what he see-feels in nature, though his principal works are visibly abstracted away from any imagery of nature $-20^{\text {th }} \mathrm{C}$ conceptual art has generally shown little interest in the specific subject of landscape.

Of the many exceptions, Land Art has articulated both environmental concerns and re-framed an idea of nature as sublime and separate from us. Richard Long, initially using the walk-poem as his medium, then photographs slight re-arrangements of found material in wilderness sites (Long, Richard., (b. 1945) A Walk in the Himalaya (1982)). These evoke relations of the man-made to our natural context, as well as extending the scope of the art gallery -- our revered locus of contemplation -- outwards and beyond to the edges of the earth. Later many of his works bring back the found 'wild' material into the gallery (Long, Richard., (b. 1945) Waterfall Line, Tate Modern (2000)). The American artist James Turrell, creates rooms with apertures where to focus us on the profound haecceity of light and astronomical phenomena above us. (Turrell, James., (b. 1943) Roden Crater (land purchased 1971, ongoing project)) His extraordinary and prolific Roden Crater project is still unfinished and kept secret.

The new medium of photography, on the other hand, has profoundly extended the scope of landscape vision making, partly through its ability to document the 'realities' of places and actions on land, partly because it has been able to overcome aesthetic prejudices towards what terrain is photographed, and significantly because it has become such a pervasive and exponentially expanding medium. In his introductory article 'Landscape and Photography' Volker Demuth writes "Within the photographically democratised image creation, with the snapping of pictures by all and sundry, reality becomes a global montage. The image pools in digital networks and clouds are growing immeasurably. In a quasi-mythical act, they are forming a second act of Creation... reality is created out of images taken rather than reality being presented in the images." (P.15 Munich Stadtmuseum., Land_scope, Photographic works from Roni Horn to Thomas Ruff in the DZ Bank Art Collection. (2018)) Landscape and Land was photography's project from its very beginning: The earliest surviving photograph of a real-world scene is Niépce's View from the Window at Le Gras (1826 or 1827) (The oldest surviving photographic image: Joseph Nicéphore Niépce's View from the Window at Le Gras (1826 or 1827)). Perhaps photography's capability to represent 'reality' and thereby occupy the field of landscape was the reason that painting moved away. But it is the breadth of 
subjects in the medium of photography that has so comprehensively expanded the idea of landscape as well.

Photography has ranged over picturesque location, sublime natural beauty, military battlefields, agriculture, cities and the (aerial) documentation of geography and space itself. Bernd and Hilla Becher had photographed post-industrial structures, eg. water towers, since the 1950's spurring numerous photographic studies of abandoned interventions and 'production landscapes'. The influential New Topographics photographic exhibition of 1975 (New Topographics: Photographs of a Man-Altered Landscape", (1975) Rochester, NY, USA) had as Ulrich Kohlmann and Christina Leber say "..revealed landscape as a venue for economic interests and alienation from nature." (P. 5 Introduction to Catalogue: Munich Stadtmuseum., Land_scope, Photographic works from Roni Horn to Thomas Ruff in the DZ Bank Art Collection. (2018)) Photographer Fay Godwin articulates deep archaeologies in the (English) landscape in her powerful account Land (Godwin, Fay., Land (1985), Heinemann). More recently photographer Nadav Kander traces the path of the $6,380 \mathrm{~km}$ Yangtse River and documents beautifully and humanely the gigantic infrastructural changes ongoing in Chongqing (For instance: The Long River, Chongqing VI (2010) by Kander, Nadav (Israeli \& South African photographer and director, b. 1961)).

The prolific large scale photographer Andreas Gursky, who was a student of Bernd and Hilla Becher, has added powerful imagery of the urban landscape and the patterns of human behavior in cities. His photographs of stock exchanges, airport halls, supermarket shelves and the serried ranks of tower blocks or container ports challenge our aesthetic prejudices and invite us to contemplate -- in 'wonderment' - the patterns of the contemporary. Flatness and repetition also become engaging, resonant propositions.

But it was perhaps photographic images of earth taken from space from the 1960's onwards that have so significantly shifted collective ideas of the reality of where we live. Our world is re-presented as tremulous, vulnerable and alone -- imagery that would powerfully support otherwise abstract scientific reports of destruction through pollution, climate change and the misuse of land. Underpinned by these visualisations, Environmentalism would extend into all aspects -- now in China too -- of economic policy, land policy and architecture too.

In his introductory article for the Chinescape photography exhibition of 2010 (in Shenzhen and Guangzhou) Gu Zheng says "Landscape photography in post-industrial society has gone way beyond the simple representation of beauty, but has elevated to the level of rethinking the destiny of the human race." (Introduction by Zeng Han: Chinescape: Contemporary Chinese Landscape Photography Exhibition, Shenzhen \& 
Guangzhou: Authentic Vision, Times Museum, 2010) In his essay Jullien does not elaborate on Environmentalism as a total, holistic perception that is inextricably linked to ideas of landscape, yet it now dominates our thinking.

As we anticipate human development in the ' $4^{\text {th }}$ Industrial Revolution' in the 'Anthropocene Age', photography has also explored landscape through digital techniques. Though radically different, this is also part of photography's heritage of selection, composition and manipulation using image-making techniques. The British photographer Dan Holdsworth painstakingly creates large scaled digital mappings of familiar terrain -for instance the Grand Canyon, the site for earlier photographers such as Ansel Adams of 'sublime' nature -- to reimagine topography and a new aesthetic environment. In his photo essay on Holdsworth's work, critic Myles Little says "the exaltation of discovery can still exist because the man-made and the sublime are not mutually exclusive." (Little, Myles., The Digital Sublime: Dan Holdsworth's Virtual Landscapes, Time Magazine, 2013)

Through landscape, environmentalism and the irreversible digital other-worlds impinging on our 'reality', as we participate in a (Demuth's) second act of Creation, we can inhabit a new terra of practice.

\section{Modern China}

In the baggage claim hall of Kunming Airport a new 150m long landscape frieze depicts aspects of the mountains, rivers, lakes, ancient towns, modern cities and the people of the immense and diverse Yunnan Province (far South West of China). The formula of the ancient landscape painting, the focus of Jullien's essay, is still alive and being re-interpreted time and time again. Numerous artists - and photographers - pursue the essence of classical Daoist thought, as an apparently boundless resource through new presentations in their work.

Again working at large scale -- her The Shape of the Wind: in Fuchun Mountains is a $2.65 \times 160$ metres long scroll - the artist (and previously a bio-medical engineer) BingYi Huang works in Chinese ink (Shui Mo), video and live performance. She explains "In my case it's not about reinterpreting Chinese traditional ink painting. If you are truly 'Shan Shui' (ie. connected to the Chinese idea of landscape) you don't need to think about it. If you are the being, you don't need to think about the being. You just are." (BingYi Huang (b. 1975, Beijing) <https://theculturetrip.com/asia/china/articles/between-heave n-and-earth-bingyi-s-meditative-ink-paintings/>). 
Yang Yongliang (Yang Yongliang (b.1980, Shanghai) (http://www.chinaphotoeducat ion.com/Carol_China/Yang_Yongliang.html) was trained in traditional ink, though now works in digital photomontage media. Large images are composed as classical landscape paintings but made from thousands of fragments of modern Chinese cities; tower blocks, factories power masts, construction cranes and motorways. Whether this is taken as a dystopian view of how far modern china has left behind the harmonies promised in classical art, whether cynical or humorous, his complex work is widely known and exhibited.

Certainly in contemporary Chinese photography, artists have stepped outside the picturesque and sentimental, inspired by western photographic explorations, to document the gargantuan appropriations, disruptions and collisions of the fast growth urban project in China. For the exhibition of contemporary Chinese landscape photography Chinescape, the catalogue essay by Yang Changjiang Holy Landscape asserts that "The aesthetics of the ancient Chinese are consisted of a strong sense of universe, time and space as well as personal emotions.." however that now "China has come to her most affluent and vulgar era.." Rapid development in China he says "..can be regarded as an unprecedented wonder.. what contemporary photography should work on is not aesthetics, but an exploration of another form of sociology and philosophy."

In the introduction critic Zeng Han writes; "Over a hundred years ago, photography was brought to China shortly after its invention along with missionaries and opium. At that time those novel and exotic images in the photographs were called 'Western-scape'. For more than a hundred years, the Chinese have long regarded the 'Western-scape' as a dreamlike goal and ideal, continuously shaping China into a real imaginary foreign country'." and that now "Chinese photographers re-examine their increasingly distorted homeland with mixed and complex feelings of love and hate."

After such rapid migration to urban areas, the bonds with the rural are more immediate and potent than in the West, which urbanized much more slowly. With policies of encouraging spare time -- for consumers to spend disposable income in -- the outflows into the countryside, with better air and fresher food, with leisurely and active pursuits, to visit and stay in scenic, cultural or just quiet locations in the vast opening country (The UK land area has twenty times the population density of China) is an established and growing socio-economic trend. Our practice has worked on numerous rural tourism projects, from small 'Mingsu' - bed-and-breakfast lodges -- to hotels, visitor centres, historic village regeneration projects and new built development as well. This growing trend is culturally underpinned -- the particular relations of people to the land and 
landscape in China are profound in Chinese ways, and as discussed earlier the heritage of ideas of nature is extensive and alive.

Rural tourism has also proved economically useful in the shift to home grown economies and a key part of poverty alleviation. "With some 2.1 billion trips made to the countryside last year (2016), the rapidly growing sector created jobs for 6.72 million rural people.." (China Daily, 11th April 2017 http://www.chinadaily.com.cn/busine ss/2017-04/11/content_28880107.htm and for example < https://link.springer.com/articl e/10.1007\{\%]2Fs11629-013-2501-3).

Investment by government in environmental remediation is rising. Protected forest and agricultural land, the presumption against green field development, interest in regeneration and repurposing buildings, and 'culturalising' urban -- and rural -- environments all form part of the 'new urbanism' of China. Mitigating and optimizing agendas encourage changes to the functions and characteristics of spaces, streets and buildings. More consultation is also coming through with the development of community scaled units of government agency, where local issues can be aired and considered (Chapter 6, Chen, Yuanzhi \& Hudson, Alan \& He, Lisheng., Chinese Urban Transformation: A Tale of Six Cities (2018)). Improvement of the public realm -- parks, squares and local public buildings -- has a higher emphasis in China than in the West.

Chinese architects, artists and photographers are emboldened by reflection on their deep cultures and experiment within societal needs and patterns of behaviour, whilst also importing -- often far too quickly -- ideas from abroad.

Cultural heritages in China are both apparent and yet disrupted by jarring imports -- not so much Collage City (Refering to Colin Rowe's book Collage City title: Rowe, Colin., Collage City (1978) with Fred Koetter) as 'Collision City'. We see our approach as participating in a renewal of cultural ideas without imitation or sentimentality. This involves numerous types of response from poetic idea to pragmatic ideas of efficacy. One way of mapping those response types is through considering possible relations between architectures and nature-landscape, which are so enticingly considered in ancient and $21^{\text {st }}$ Century China.

\section{Nature-Relational Architectures}

We have numerous starting points to experiment with in landscape relations - numerous ways of re-accommodating with our environments 


\subsection{The Pavillion}

Pavillions in the Chinese landscape depiction present a primal attitude that architects revisit time and time again -- from the frontality of the Greek temple to Johnson House's glassy transparency. We are completing a small MingSu (lodge) above Chongqing where windows differently frame the view of trees and distant hills. Here we can sit poised at the potent threshold between the comfort of 'home' and the bountiful resource of nature. This architecture may be simplified, reduced to a rudimentary frame to lightly accommodate without visual intrusion -- it is our relations with the outside that has come in that gives the spatial essence.

\subsection{Accommodations}

Profoundly influential to so many architects, Alvar Aalto's modernity promises new accommodations with the natural world. Using a courtyard and atrium plan, we are working on a public hospital outside Chongqing that in a direct way tries to engage with the wooded embankment of a small river next to the site. New gardens, roof terraces and planted balconies, that draw not only on the culture of relations with nature but also the proven benefit of adjacency to green space for good health, and holistic ideas in Chinese medicine still practiced in hospitals today.

\subsection{Allusional}

We can imply, symbolize or represent nature through form and materiality. Our project for an Arts Centre above a lake in beautiful mountain scenery is a floating pyramidal form alluding to the terrain of the site. It suggests a large boulder and windows and lighting beneath the gauze of its exterior finish suggest a lantern -- a potent cultural object. The combination of allusions is intended to enrich the implications of a sculptural intervention. The project tries to engage with the land directly whilst in an abstract way remaining man-made.

Another project nearby -- a visitor centre and main gate -- more literally announces the mountain, forest and pastural scenic features of the area and is shaped like a child's drawing of a hill and has clusters of columns made from the trunks of trees nearby. 


\section{4. as Landscape}

Perhaps best consummated in Foreign Office Architect's Yokohama Cruise Terminal (from 1995), or so much of Zaha Hadid's work, the narrative of building as a landscape has been a powerful and ongoing inspiration for architects. On our part, a first prize winning scheme for the Orestad extension of Denmark was 'grown' around hillocks made from the spoil from the construction of the Oresund bridge. In Nizhny Novgorod, our scheme for the Sochi Olympics ski jump training, sports and retail complex (2009) embeds itself with its bulk disguised by fluid roof forms merging with the natural topography of the banks of the River Volga.

\subsection{Greened}

Environmental threat, climate change, finite resource depletion, water and air pollution are the crises of today, systematically communicated through imagery. Architects were able to move beyond the merely stylistic confrontations fought between for example classicists, modernists and post modernists and instead focus on the new imperatives of building 'sustainably' and framed their thinking with another form of re-accommodation with the wider natural world. The functional requirements of sustainable construction were to create new aesthetics.

Jullien asserts that ideas of landscape are appropriate also for other terrains such as cities and warns against 'atony' and flatness. In McFarlane's Landmarks (McFarlane, $R$. (2015) Landmarks) which records lost words in the landscapes that we are retreating from, the writer talks about impending 'blandscape' - the indifference to the distinction between things - and the need for 're-wonderment'. If then an ideal city is a plural, diverse phenomena, and the site of many different people interacting, then many architectures -- such as those above - would cohabit there.

\subsection{The Path and Street}

The path in classical Chinese painting, literature and mythology has had high importance. The visual device of the path wanders us through the landscape to help us imagine our physical-spiritual journey of changing phenomena and emotion. It leads us through and behind and on to the lonely pavilion, where we can imagine shelter and comforts amongst and at peace with nature. Here we travel alone or with friends, here we meet farmers, fishermen, monks, musicians, scholars - the world of our human 
relations is included as part of our realities. This idea of path -- sometimes a prescribed route - is similarly prominent and practically speaking useful in the classical Chinese garden.

Was this path also so important an idea given the much longer distances travelled in such an extensive nation? Unlike the Cathedrals within the European city, major temples in China tend to be remote - often on mountainous sites. Pilgrimage and travel involving lengthy sacrifice then would have given a crucially different perception of territory. Many events and encounters in myths and literature take place on the way -- such as Journey to the West ( Journey to the West is one of the 4 classic Chinese novels, attributed to Wu Cheng'en (c. 16th Century, undated)) Today people are very willing to make long journeys for their modern pilgrimages for study, work or pleasure -- the mass migrations at the Chinese New Year holidays for instance.

China's consolidation as the immense 'Middle Kingdom' with increasing command, communication and trade would have been dependent on good road networks. Now, modern China has placed high emphasis on investment in new infrastructure, with extensive motorway and high-speed rail systems. One of its most tangible foreign policies is the Belt and Road initiative (For instance: <https://www.lowyinstitute.org/sites/de fault/files/documents/Understanding\%20China's\%20Belt\%20and\%20Road\%20Initiativ e_WEB_1.pdf>), involving new rail and road connections to South East Asia, Pakistan, Iran, the Middle East and Europe as a new 'Silk Road'. (Comparatively, Mediterranean and European civilisations placed greater emphasis on maritime communication)

Classical Chinese art does not depict the street -- the urban pathway - so extensively as it does landscapes, but when it does these are busy places of interaction, with shops, inns, shrines, gated courtyards and gardens. Modern Chinese film frequently uses the street as the setting for historical drama using the interplay between public space, shared space and private rooms that is the subtle pattern of assembled streets and courtyards. Urban tourist attractions such as preserved historic shopping streets, or pedestrianized quarters in China, are popular and economically successful. Those patterns however have been largely absent in the late 20thC city city plan formula, partly through the use of ghetto-like zoning of gated 'communities'. These are large blocks of land for a limited range of housing types which are separated from roads by security fencing.

If the physical and social material of the pathway connection is elevated both as a cultural space and as imperial efficacy, and where the pluralities of architecture co-exist too -- could this be useful in our thinking on future Chinese urban form? 
Certainly in the West, the humanization of the city through investment in the public domain, re-thinking the road and pedestrian friendly urban design has been tangibly beneficial. Zaha Hadid Architects -- unexpectedly for the sculptural work they are usually known for -- have presented 'Walkable London: Upgrading the urban prosperity engine' at London's New London Architecture centre. (See: <https://www.newlondonarchitectur e.org/whats-on/events/2018/january-2018/walkable-Iondon-zaha-hadid-architects>). In the high streets of Europe, the shop -- always taken as more cultural than a merely commercial unit of space -- is being transformed through internet based purchasing and different modes of work and interaction. There the booming café has expanded into a multi-functional space for solitary and group activities for a wide range of people. In China tea houses and casual restaurants are also re-configuring and multiplying for more diverse modes of behaviour as a symptom of new home-grown economies. Accessed by a dramatic copper clad escalator enclosure, the basement FanGuo bookshop below the new TaiKoo Li shopping quarter in Chengdu extends to some 10,000sqm and has cafes, art and craft stalls, clothing, technology, reading areas and book sales. Hybrid commercial, social and cultural functions are emerging, perhaps just as Japan experienced in its flowering of new products in the 1980's and 1990's. This home-grown and hybridising trend in China is encouraged and financially supported by central and local government.

\section{Conclusion}

This paper is motivated by the formless practice of architecture, especially in China, as the demands of the day-to-day and the diversity of design briefs constantly redirect us. At the same time the city is both expanding and changing with oncoming new modes of occupation, and where the hardware of buildings and the flows of human interaction are unbalanced.

Starting from Francois Jullien's philosophical essay Living off Landscape, we have looked at the ideas of landscape that underpin attitudes and aspirations for finite physical and cultural contexts. That essay illustrates limitations to European landscape thought but leaves unanswered the questions of how the modern world has continued. Photographic media, especially in the West, has certainly added and extended out thinking on land and, by considering the method and tactics of looking and seeing, also developed new scopes in the field and new aesthetics. Photography has underpinned overarching concerns about the vulnerability of an isolated and probably unique planet, 
and become a primary medium through which environmentalism has been communicated and now embedded in how we perceive our world.

Much of this world-wide thinking has been shared with the modern Middle Kingdom, which remains open to assimilating ideas -- now more critically - from beyond. In China, problematic disconnections persist between the enduring cultural ideas of landscape as an ideal and explanation of fluid reality, the 'heavy modern' post-war project of formulaic industrialization and urbanization and rising ideas of social enrichment and optimization in the new urbanism.

Repositioning, then re-evaluating the cultural function of terrain gives our practice specific tools to help enhance the significance of designs and buildings for dwellers and viewers. In the process of acknowledging the ancient Chinese idea of nature-reality, the relations of the building to nature and landscape have become more crucial.

Those relations can take many forms: The simple pavilion, the building that accommodates nature, that symbol of the natural, mimicry of natural form, greened buildings or of a digitally manufactured nature.

In the vast ancient region of China the path has been and still is a pronounced cultural, practical and administrative structure. By extension the 3-dimensional site of the adapting street offers many possibilities for re-thinking as the place for all-ages, new behaviours and the fluid interaction of the society met along the way.

Here too, in the Anthropocene, an era of probable less work through automation and / or different work-life patterns with unimagined new industries, the street needs to flex and adapt more fluidly, include, and nourish us with more soulful participation.

Matthew Priestman, revised: 10 May 2019

I am very grateful to Kester Rattenbury, Giulio Verdini and Pamela Kember who gave their valuable inputs to the manuscript and helped in completing the paper.

The paper has been funded by the author and the author has no conflict of interest to declare.

Note on the title 'Mountain Waters': The title uses the two words freely so as to be more evocative of the overall themes of the paper. It is not intended as a direct translation of the Chinese word for landscape which is literally Mountain(s) Water(s)

\section{References}

[1] Jullien, F. (2018). Living off Landscape, or the Un-thought of in Reason. Lanham, Maryland, USA: Rowman \& Littlefield International. 
[2] De Botton, A \& Armstrong, J. (2013). Art as Therapy. London [etc.]: Phaidon.

[3] Stadtmuseum, Munich. (2018). Land_scope, Photographic works from Roni Horn to Thomas Ruff. Munich: Snoeck.

[4] Jenkins, W. (1975), New Topographics: Photographs of a Man-Altered Landscape. Catalogue. Rochester, NY: International Museum of Photography at the George Eastman House

[5] Godwin, F. with an essay by Fowles, J. (1985), Land. London: Heinemann.

[6] Kander, N \& Tchang, J.P. (2010). Nadav Kander: Yangtse, The Long River. Berlin: Hatje Cantz.

[7] Han, Z. (2010). Chinescape: Contemporary Chinese Landscape Photography Exhibition, Shenzhen \& Guangzhou. Guangzhou, China: Authentic Vision, Times Museum.

[8] Myles, L. (2013). The Digital Sublime: Dan Holdsworth's Virtual Landscapes, Time Magazine, January 08

[9] Guest, L. (2017). Between Heaven And Earth: Bingyi's Meditative Ink Paintings. The Culture Trip, May 04

[10] Carter, C. (2019). Yang Yongliang. Chinaphotoeducation.com, retrieved May 10

[11] Chen, Y., Hudson, A. \& He, L. (2018). Chinese Urban Transformation: A Tale of Six Cities. London: RIBA Publishing

[12] Rowe, C. \& Koetter, F. (1978). Collage City. Cambridge, Massachusetts and London: The MIT Press.

[13] McFarlane, R. (2015). Landmarks. London: Hamish Hamilton, Penghuin. 